\title{
Transport of short-chain perfluoroalkyl acids from concentrated fluoropolymer facilities to the Daling River estuary, China
}

\author{
Pei Wang • Yonglong Lu • Tieyu Wang • Zhaoyun Zhu • \\ Qifeng Li • Yueqing Zhang • Yaning Fu • Yang Xiao • \\ John P. Giesy
}

Received: 5 October 2014 / Accepted: 7 January 2015 / Published online: 24 January 2015

(C) Springer-Verlag Berlin Heidelberg 2015

\begin{abstract}
After global commercialization of short-chain perfluoroalkyl acids (PFAAs) as substitutes to conventional long-chain PFAAs by the major manufacturers, two fluorine industry parks for production of short-chain PFAAs located in the Daling River Basin of northern China have developed rapidly in the last few years. This study provides a systematic assessment of sources, emissions, transportation, and potential risks of the PFAAs in this area. The C4 perfluorobutane sulfonic acid (PFBS) and perfluorobutanoic acid (PFBA) were the predominant short-chain PFAAs in river water, with maximum concentrations of 2.90 and $1.35 \mu \mathrm{g} / \mathrm{L}$, respectively. Park 1 equipped with a telomerization process was identified to be the source of linear and branched mixtures of PFBS, PFBA, and perfluorooctanoic acid (PFOA), while park 2 with an electrochemical fluorination process (ECF) was identified to be the source of linear and branched mixtures of PFBS and PFOA. Partition coefficients between water and sediment were consistent for C4-C8 perfluoroalkyl carboxylic acids (PFCAs) but directly proportional to C9-C11 PFCAs and perfluoroalkyl sulfonic
\end{abstract}

Responsible editor: Leif Kronberg

Electronic supplementary material The online version of this article (doi:10.1007/s11356-015-4090-x) contains supplementary material, which is available to authorized users.

P. Wang $\cdot$ Y. Lu $(\triangle) \cdot$ T. Wang $\cdot$ Z. Zhu $\cdot$ Q. Li $\cdot$ Y. Zhang $\cdot$ Y. Fu $•$ Y. Xiao

State Key Lab of Urban and Regional Ecology, Research Center for Eco-Environmental Sciences, Chinese Academy of Sciences,

Beijing 100085, China

e-mail: yllu@rcees.ac.cn

P. Wang $\cdot$ Z. Zhu $\cdot$ Q. Li $\cdot$ Y. Zhang $\cdot$ Y. Fu $\cdot$ Y. Xiao

University of Chinese Academy of Sciences, Beijing 100049, China

J. P. Giesy

Department of Veterinary Biomedical Sciences and Toxicology

Centre, University of Saskatchewan, Saskatoon, Saskatchewan,

Canada acids (PFSAs). Analysis on the health risk of PFBS and PFBA suggested that they were not without risk since short chain PFAAs are known to be recalcitrant during water treatment.

Keywords Perfluoroalkyl acids · Fluoropolymer facilities . PFBS · PFBA · Partition coefficient · Daling River Basin

\section{Introduction}

Perfluoroalkyl acids (PFAAs) are synthetic, fully fluorinated chemicals that are characterized by a perfluoro-alkyl chain and a terminal group. Carboxylate acids (PFCAs) and sulfonate acids (PFSAs) groups are the most widely produced PFAAs and consequently found in predominant quantities in the environment (Buck et al. 2011). PFAAs are persistent due to the high-energy carbon-fluorine (C-F) bond (Giesy et al. 2010). Toxicity and bioaccumulative potential of PFAAs are directly proportional to length of the fluorinated carbon chain (Conder et al. 2008; Olsen et al. 2009), while solubility in water is inversely proportional to length of the perfluoroalkyl chain (Prevedouros et al. 2006; Armitage et al. 2009). Among the different PFAAs produced, the C8 perfluorooctane sulfonic acid (PFOS) and perfluorooctanoic acid (PFOA) were mostly produced and widely distributed and posed great risks of health concern (Lau et al. 2007; Houde et al. 2011; Lindstrom et al. 2011; Olsen et al. 2012). As a result, even though there was no evidence of adverse effect, in 2000, the $3 \mathrm{M}$ Company started to voluntarily phase out the production of PFOA, PFOS, and PFOS-related products (3M 2000). In 2006, the US EPA invited eight leading companies to participate in a stewardship program to reduce use and emission of PFOA and related substances by 2010 and work toward final elimination by 2015 (USEPA 2006). In 2006, the European 
Union restricted use of products containing PFOS (EC 2006). In 2009, PFOS, its salts, and perfluorooctane sulfonyl fluoride were listed in appendix B of the Stockholm Convention on Persistent Organic Pollutants (POPs) (UNEP 2009). As a signatory of the Stockholm Convention, China began implementation of control over PFOS and related chemicals in 2009. Until now, the action has been focused on review of production, sale, and usage and how substitutes can be introduced. Since 2003, a lot of studies in China have been conducted on occurrence of PFASs in different matrices including soil, water, sediment, biota, food stuff, human blood, etc. (Wang et al. 2014b). General industrial and domestic emissions of PFOS have also been evaluated (Xie et al. 2013a, b). However, information related to fluorine industries, their direct emission, and environmental consequences is still very limited. In addition, there is still no governmental constraint on use or emission of PFAAs in China (POPs Action in China 2014).

The C4 and C6 chemicals have been frequently used to replace most applications previously met by use of $\mathrm{C} 8$ and greater chain-length homologues (Holt 2011). Consequently, production of short-chain PFAAs has increased rapidly in recent years (Oliaei et al. 2013). The presence of short-chain PFAAs in the environment and drinking water (Kwok et al. 2010; Moller et al. 2010; Wilhelm et al. 2010; Eschauzier et al. 2013) and sediments (Codling et al. 2014) has already been reported. While in China, high levels of perfluorobutane sulfonic acid (PFBS) and perfluorobutanoic acid (PFBA) have been reported in surface water of Tangxun Lake, with potential sources from untreated industrial wastewater and WWTP effluents (Zhou et al. 2013), which also brought high exposure to local fishery employees (Zhou et al. 2014).

In recent years, production of PFAAs-related chemicals has increased rapidly in China. For example, production of PFOSrelated chemicals has grown from $30 \mathrm{t}$ in 2001 to $250 \mathrm{t}$ in 2006, and kept almost consistent until 2011 (Xie et al. 2013b). Two fluorine industry parks located in Fuxin City, Liaoning Province, were built in 2004 (park 1) and 2006 (park 2) for production of PFAAs (Fig. 1). Emissions of eight PFAAs from park 1 in the ambient environment and the local residents were investigated in 2009 (Bao et al. 2010). Results of that study indicated that PFOA was the predominant PFAA followed by PFBS. However, construction is still underway for expansion and will last for several years. This could have resulted in dynamic changes in patterns of production and possible emissions of PFAAs from the two parks. Considering the persistence and mobility of PFAAs in water, research on the areas affected by the two parks was deemed to be updated with expanded scale, especially for the dischargereceived rivers, which are Xihe River and Daling River.

Found in a systemic assessment conducted in 2008 on water, sediments, and adjacent soils of coastal rivers draining into North Bohai sea, the concentrations of PFAAs were greatest in the Daling River (Wang et al. 2011), and the two parks posed a

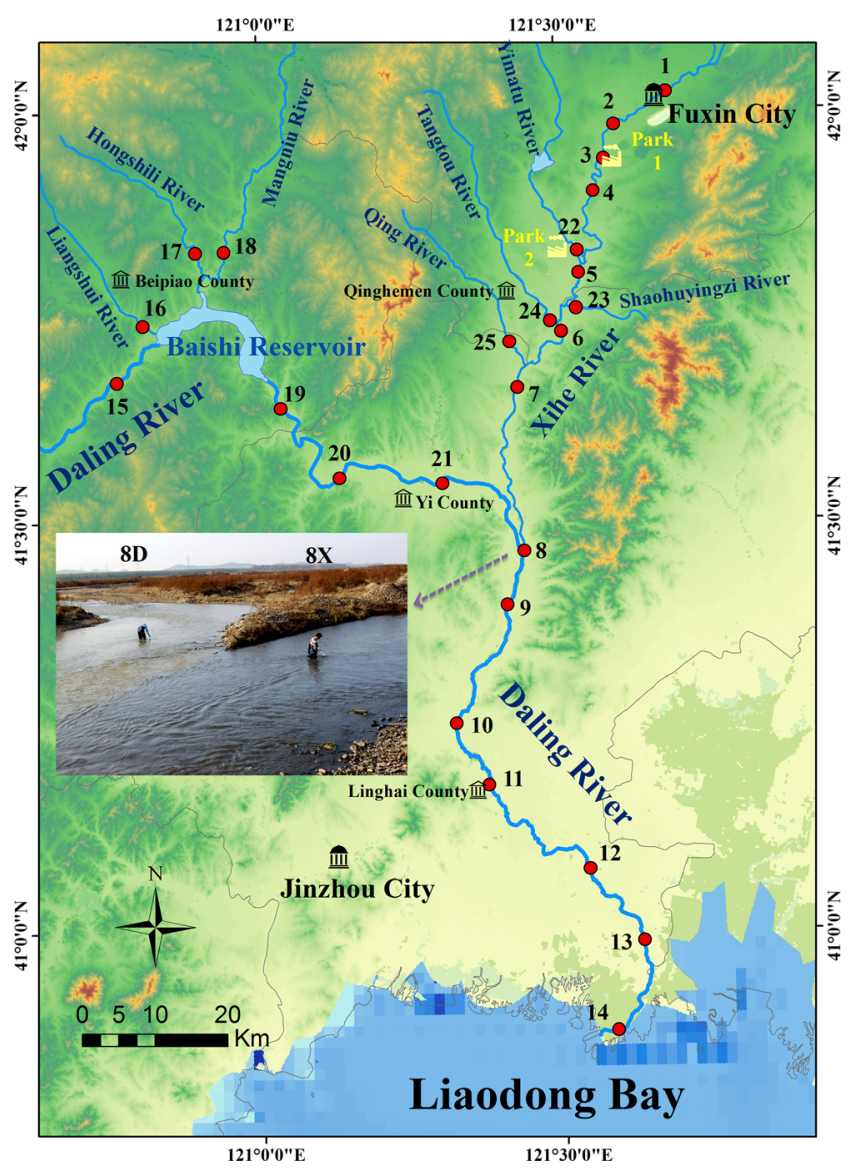

Fig. 1 Sampling sites (red plots) in the Daling River basin, China

great potential as the sources to the PFAAs detected in soils (Wang et al. 2013b). This paper is an extension to the systematic research with the objective to trace influences of the two rapidly developing parks on most part of the Daling River Basin and study the transport and fate of PFAAs as well as the risk assessment from point source to estuary along the river.

\section{Materials and methods}

\section{Sampling campaign}

From October 11-19, 2011, samples of surface water and sediment were collected from 25 sites along the Daling River and its four tributaries as well as four tributaries of the Xihe River (Fig. 1). The distance from site 1 to site 8 is $82 \mathrm{~km}$ and from site 8 to site 14 is $90 \mathrm{~km}$. Samples of surface water (top 1-20 cm) were collected using $1 \mathrm{~L}$ polypropylene (PP) bottles. Sediments (top 1-5 cm) were collected using a stainless steel trowel, and then stored in clean 250-mL PP boxes. All samples were kept on ice for transport. Before analysis, sediment samples were freeze-dried and ground through 2$\mathrm{mm}$ mesh. Non-suspended substances in water samples were 
removed by defecating for $24 \mathrm{~h}$. All samples were extracted within 2 weeks after arriving in the lab. Detailed information on sampling was given in Supplementary Material.

Extraction, identification, and quantification of target analytes

Seventeen PFAAs including 13 PFCAs and 4 PFSAs were investigated (Table S3). A volume of $400 \mathrm{~mL}$ of unfiltered water was extracted by use of OASIS WAX solid-phase extraction (SPE) cartridge $(6 \mathrm{cc}, 150 \mathrm{mg}, 30 \mu \mathrm{m})$ (Taniyasu et al. 2005). For sediments, $2 \mathrm{~g}$ of dry mass (dm) samples were extracted by use of ultra-sonic extraction with methanol followed by clean-up with ENVI-Carb and OASIS-WAX cartridges (Loi et al. 2011). Detailed information on extraction is given in the Supplementary Material. Individual PFAA was separated and quantified by use of an Agilent 1290 Infinity HPLC System coupled to an Agilent 6460 Triple Quadrupole LC/MS System (Agilent Technologies, Palo Alto, CA) that was operated in the negative electrospray ionization (ESI) mode. The instrument conditions were listed in Table S4.

\section{QA/QC}

In order to monitor potential contamination, a series of blanks, including field, transport, procedure, and solvent blanks were prepared with every sample batch. Quantification of 17 PFAAs in water and 11 PFAAs in sediment was carried out using 9-point external and internal quantification curves with concentrations of native standards ranging from 0.01 to $100 \mathrm{ng} / \mathrm{mL}$, respectively. The regression coefficients $\left(R^{2}\right)$ for all the target analytes were over 0.99 . The injection volume of the extract was $5 \mu \mathrm{L}$. The limit of detection (LOD) and limit of quantification (LOQ) were defined as the peak of analyte that needed to yield a signal-to-noise $(\mathrm{S} / \mathrm{N})$ ratio of $3: 1$ and 10:1. LOD and LOQ ranged from 0.002 to $0.02 \mathrm{ng} / \mathrm{g}$ and from 0.01 to $0.1 \mathrm{ng} / \mathrm{g}$, dm for sediments. For water samples, LODs ranged from 0.01 to $0.13 \mathrm{ng} / \mathrm{L}$, while LOQs ranged from 0.06 to $0.63 \mathrm{ng} / \mathrm{L}$. Matrix spike recoveries ranged from 75 to $110 \%$ for water samples and 73 to $119 \%$ for sediment samples. Procedure recovery ranged from 77 to $122 \%$ for water samples and 78 to $120 \%$ for sediment samples. For concentrations of PFAAs in any extract measured over $100 \mathrm{ng} / \mathrm{mL}$ for the first time, fewer volume or weight of samples would be taken and extracted again to make sure that the concentrations in the final extracts would fit in with the range of the calibration series. Detailed QA/QC measurements of PFAAs are given in the Supplementary Material.

Statistical and spatial analysis

Statistical analysis was performed with SPSS Statistics V20.0 (SPSS Inc. Quarry Bay, HK). Normality was confirmed by the Kolmogorov-Smirnov test and homogeneity of variance was confirmed by use of Levine's test. During the analysis, concentrations less than the LOQ were set to a value equivalent to half of the LOQ, and those less than the LOD were assigned values equivalent to the $\mathrm{LOD} / \sqrt{2}$ (Calafat et al. 2007). Positions of sampling sites and spatial distributions of concentrations of PFAAs were performed with the Arcmap module in ArcGIS V10.0 software (ESRI, Redland, CA).

\section{Partition coefficient analysis}

Partition coefficients were calculated based on published methods (Ahrens et al. 2010). The sediment-water partition coefficient $\left(\log K_{\mathrm{d}}\right)$ was calculated using Eq. 1.

$\log K_{\mathrm{d}}=\log C_{S} / C_{W}$

where $C_{S}$ and $C_{W}$ are the concentrations of PFAAs in sediment $(\mathrm{ng} / \mathrm{g})$ and water $(\mathrm{ng} / \mathrm{mL})$, respectively. The organic carbon fraction $\left(f_{\mathrm{OC}}, \%\right)$ normalized partition coefficient $\left(\log K_{\mathrm{OC}}\right)$ was calculated using Eq. 2.

$\log K_{\mathrm{OC}}=\log \left(K_{\mathrm{d}} \times 100 / f_{\mathrm{OC}}\right)$

\section{Results and discussion}

Distribution of PFAAs in surface water of Daling River Basin

PFAAs were detected in all surface waters with concentrations of sum PFAAs ( $\sum$ PFAAs) ranging from 1.01 to $4.74 \mu \mathrm{g} / \mathrm{L}$ (Table S6). PFBS (0.2 to $70.6 \%, 35.9 \%$ on average) and PFBA ( 8.0 to $87.4 \%, 32.8 \%$ on average) were the predominant PFAAs, followed by PFOA (1.8 to $63.5 \%, 17.5 \%$ on average). In site 2, PFBA, PFOA, and PFBS accounted for $96 \%$ of the $\sum$ PFAAs. These are the largest concentrations of PFBS and PFBA reported in rivers of China so far (Wang et al. 2013a). In order to better understand source and transport of PFAAs within the Daling River Basin, the study area was divided into four sections: (1) the Xihe River where the two fluorotelomer industry parks are located, from site 1 to site $8 \mathrm{X}$; (2) four tributaries of the Xihe River, to find potential emissions, from site 22 to site 25; (3) the Daling River before its confluence (at site 8) with the Xihe River, from site 15 to site 21 and site 8D; and (4) after its confluence with the Xihe River, from site 9 to site 14 (Fig. 2).

From site 1 to site 2 in the Xihe River, concentrations of PFBA, PFOA, and PFBS all increased, this indicated that there were small-scale sources in the upstream of the Xihe River or in the city of Fuxin. Between site 2 and site 3, which is located downstream of one of park 1's wastewater effluents (effluent 1), concentrations increased from $144 \mathrm{ng} / \mathrm{L}$ to $962 \mathrm{ng} / \mathrm{L}$ for PFBA and from $19.5 \mathrm{ng} / \mathrm{L}$ to $1.82 \mu \mathrm{g} / \mathrm{L}$ for PFBS, respectively. But for 
Fig. 2 Concentrations of PFAAs $(\mathrm{ng} / \mathrm{L})$ in surface waters of the Xihe and Daling Rivers and their tributaries

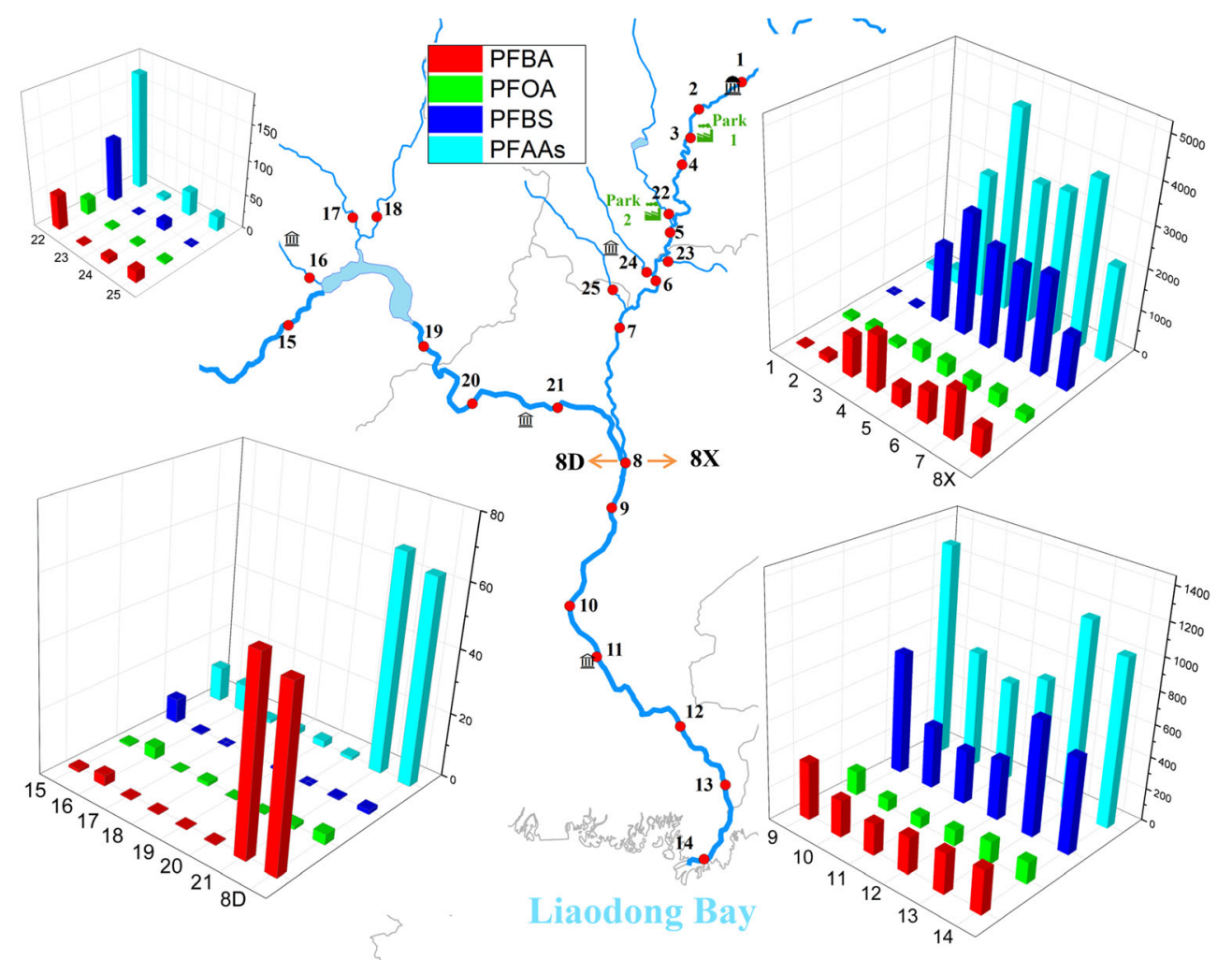

PFOA, the concentration decreased from $167 \mathrm{ng} / \mathrm{L}$ to $102 \mathrm{ng} / \mathrm{L}$. This indicated effluent 1 was a major source of PFBA and PFBS. From site 3 to site 4, concentrations of several PFAAs increased. This result was consistent with that of a previous study conducted in 2009 in which another effluent (effluent 2 ) in park 1 located between site 3 and site 4 was found to be a major point source of PFOA (Bao et al. 2010). At this time, effluent 2 was also a major point source of PFBS and PFBA as well as PFOA. From site 4 to site 5, the Yimatu River joined the Xihe River; levels of PFBS, PFBA, and PFOA changed 1.2, 3.0, and 1.0 times, respectively. The almost unchanged levels of PFOA and PFBS indicated that park 2 was a major point source of both PFOA and PFBS. However, concentrations of PFAAs at site 22 on the Yimatu River were 19 times lower compared with those at site 5 in the Xihe River, which implied that park 2 was emitting sewage directly to the Xihe River. Between site 5 and site 7, concentrations of PFAAs were consistent from $3.26 \mu \mathrm{g} / \mathrm{L}$ to $3.97 \mu \mathrm{g} / \mathrm{L}$, and concentrations in water from sites $23(5.26 \mathrm{ng} / \mathrm{L}), 24(35.8 \mathrm{ng} / \mathrm{L})$, and 25 $(21.3 \mathrm{ng} / \mathrm{L})$ indicated no input from the three tributaries. Concentration of PFBA increased gradually from $455 \mathrm{ng} / \mathrm{L}$ in site 5 to $1.15 \mu \mathrm{g} / \mathrm{L}$ in site 7 along the Xihe River. There were two reasons for the stable levels ofPFOA and PFBS from site 5 to site 7. First, the discharge from the tributaries was much less than that of the Xihe River, so the dilution effect was not obvious; secondly, fluorine industry was strongly supported by the local government; even if the facilities were mostly concentrated in the two parks, there might be small-scale facilities along the river, which would bring emissions of certain PFASs to the Xihe River. At site 8, concentrations of PFAAs were diluted almost by half by some unmeasured tributaries at the downstream of site 7. After the confluence of the Daling and Xihe Rivers, concentrations of PFAAs were diluted by a factor of two, and then remained constant until the river discharged into the estuary at site 14. In the Daling River, upstreamofsite 8D, PFAAswere detected infrequently except for a small amount of PFBA emitted from Yi County (site 21). Results from the four sections suggested that PFAAs in the Daling River came from the two parks located on the Xihe River where outfalls emitted sewage directly to the Xihe River and little PFAAs were contributed from the other tributaries. The concentrations of PFFAs were diluted after the Daling River converged with the Xihe River.

Recently, PFOA has been found to be the dominant PFAA in coastal rivers of Northern Bohai Bay (Wang et al. 2011) and South Bohai Bay(Wang et al. 2014a), rivers in Tianjin city (Pan et al. 2011), and the Hanjiang River (Wang et al. 2013a). But, there was little information on short-chain PFAAs such as PFBA and PFBS, largely due to their recent emergence. Only Tangxun Lake presented levels of PFBS and PFBA as high as those in this study (Zhou et al. 2013). Even for the study conducted on effluent 2 of park 1 in 2009, PFOA and PFBS were identified to be the predominant PFAAs (Bao et al. 2010). However, after 2 years, concentrations of PFBS in the Xihe River increased 6.9-fold and PFOA increased 3.7fold (Fig. 3), and great concentrations of PFBA were also 
Fig. 3 Comparison of concentrations of PFAAs in this study with those from Bao et al. (site A and G) conducted in 2009 (a) and Wang et al. (Site JZ3, JZ4, and JZ5) conducted in 2008 (b)

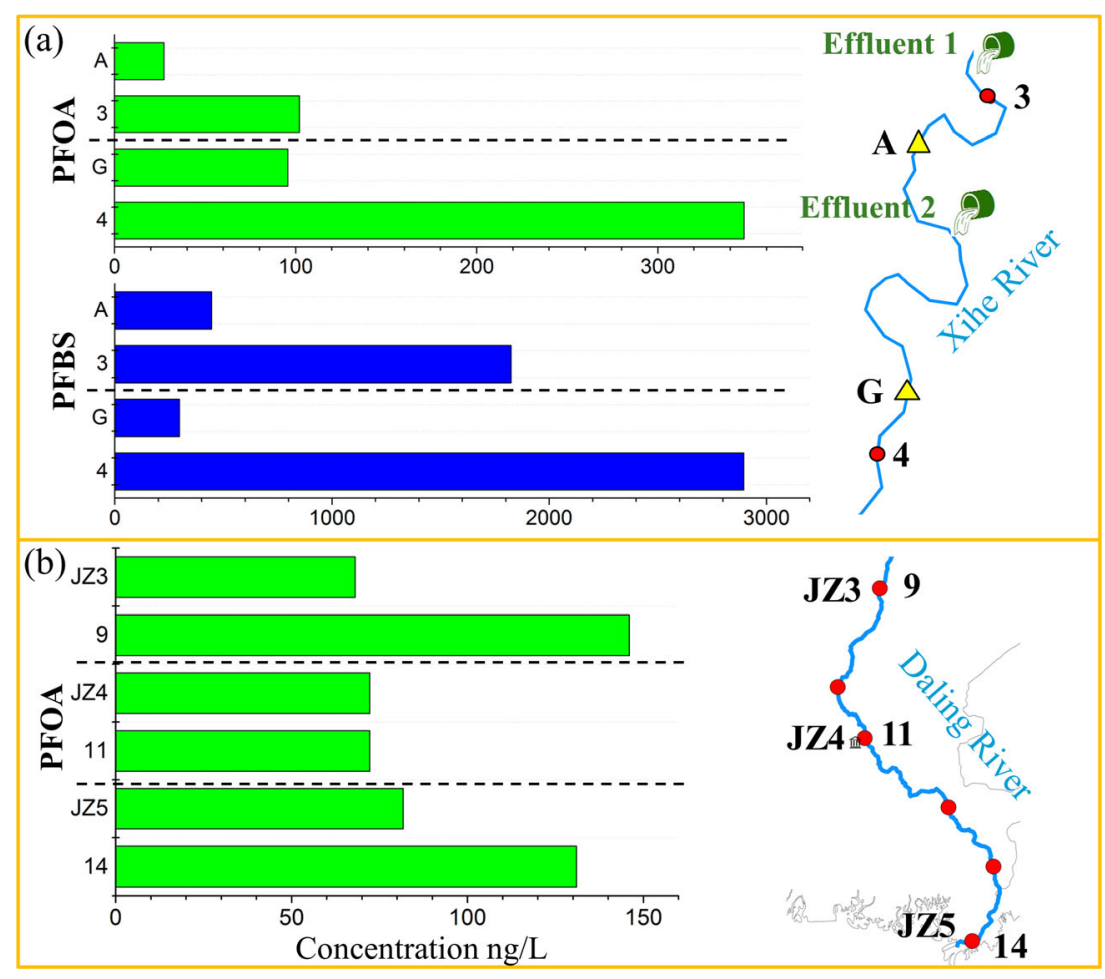

observed. Considering the rapid and consistent expansion of fluoropolymer facilities in the two parks, the main products, and the increasing levels of PFASs from 2009 to 2011, these results indicated rapid growth of production and application of short-chain PFAAs in the two parks. In a study in Minnesota (USA) during the period 2002 to 2006 , relatively great concentrations of PFAAs were found in wastewater effluents of the $3 \mathrm{M}$ plant that were directly discharged into the Mississippi River (Oliaei et al. 2013). PFBS was the dominant PFAA with concentration as great as $120 \mu \mathrm{g} / \mathrm{L}$, which was almost 40-fold greater than that observed in this study. These results are consistent with that of studies on dated sediment cores in which concentrations of PFBS have been found to be increasing in recent years while concentrations of PFOS are decreasing (Codling et al. 2014). With short-chain PFAAs continuing to be produced and used in the world, it is necessary to monitor the production and emission processes in the two parks continuously.

Identification of potential sources associated with the two parks

Production and use of organofluorine compounds at the two parks were investigated in 2011 (Wang et al. 2013b); since then, dozens of additional facilities have been added to the two industrial parks. The data presented here allows for an assessment of emissions of PFAAs from the new facilities as well as efficiency of emission mitigation. Many facilities have been used to produce intermediates like fluorobenzene for use in pharmaceutical drugs, pesticides, and dyes, but limited information is available on their relationship with PFAAs emissions. In park 1 , there is one facility (F1) producing various fluoropolymers and fluorotelomers. For fluoropolymers, the main products include fluorinated surfactant used for fabric finishing agents and leather treatment and polytetrafluoroethylene (PTFE) with an annual capacity of 1200 tons for suspension PTFE resin and 600 tons for dispersion PTFE resin, respectively (Fuxin Fluorine Industry Development Zone 2012). Ammonium perfluorooctanoate (APFO) is known to be used in dispersion polymerization processes for making PTFE from TFE, which can bring emission of PFOA to the environment (European Commission 2010). This is consistent with the observation of PFOA emissions in outfall 2 of park 1 (Bao et al. 2010). Another kind of key products for F1 was fluorotelomers, including $(n=2)$ fluorotelomer alcohol $(\mathrm{FTOH})$ produced in telomerization (TM) process using perfluoroalkyl iodide (PFAI) and tetrafluoroethylene (TFE), with an annual capacity of 3000 tons. According to the manufacturer, fluorotelomers included various perfluoroalkyl telomers and monomers with even numbers of carbons and chain lengths from 2 to 12 or longer. Those with 6 or fewer carbons in the perfluoro-moiety are liquids at standard temperature and pressure so they are prone to spill and to be emitted to water, while longer-chain PFAAs would be emitted as solid waste. This is also consistent with the observation in effluent 1 of park 1 , where concentrations of PFBA and PFBS have increased with production of these two chemicals. However, the emissions of a fluorotelomers manufacturer are very complex and not limited to water and 
solid waste. For example, some FTOHs are volatile. In addition, the emissions are not limited to PFAAs. There are several PFASs with chemical properties not directly related to the length of the perfluorinated chain. In park 2, the largest facility (F2), which was built in 2002, has been producing fluoropolymers by use of electrochemical fluorination (ECF) for several years, with the main products including PFBA, potassium-PFBS, perfluorobutanesulfonyl fluoride (PFBSF), PFOA, and APFO (Fuxin Fluorine Industry Development Zone 2012). Potential emissions of related PFAAs from F2 to the river were also consistent with observations at sites 5, 6, and 7 in this study. Other facilities, without direct production of perfluoalkyl substances, would use them as raw materials or additives. And, this might also be a heavy source of PFASs emission. Consistent with the results of this study, the main PFAAs produced or used in the two parks were PFBS, PFBA, and PFOA, and the others were mostly byproducts (Table 1).

The two processes used to produce fluorotelomer substances generate different profiles of isomers. Historically, ECF was used to synthesize PFOS and PFOA, with about 70-80 \% linear and 20-30\% branched isomers, respectively. As a primitive technology, ECF would also generate complex mixtures of homologues with 4 to 9 carbons and other intermediates or by-products, some of which were regarded as precursors of PFAAs (Paul et al. 2009). ECF process is now used to make alternative products like PFBS and PFBA at F2 based on perfluorobutane (Buck et al. 2011). The standards used in this study were all for linear isomers. Although branched isomers account for the minor portion of the total, if they were included, it would result in greater concentrations of $\sum$ PFAAs, even greater in the effluent of park 2 and in the river. F1 used TM process, according to Buck et al. 2011, when a linear telogen is used, linear PFASs are obtained with the TM process and vice versa (Buck et al. 2011). However, branched isomers could also be generated during this process, which could be illustrated by the chromatogram of the three predominant PFAAs in the water of site 3 (Fig. S2). According to the same study, the extent to which branched telogen may have been actually used in commercial practice is unclear. Nevertheless, when branched PFCA isomers (isopropyl mainly) were detected in environmental samples, their levels were low compared to their linear counterparts. So, effluent 1 was also the source of linear and branched PFAAs (Table 1). Furthermore, there were predictably more per- and poly-fluorinated substances in the effluent water, which should not be ignored in the future studies.

Partition of PFAAs between water and sediment along the transport route

For the ionic PFAAs detected in this study, the main reservoir and transport routes are the rivers. The primary route to

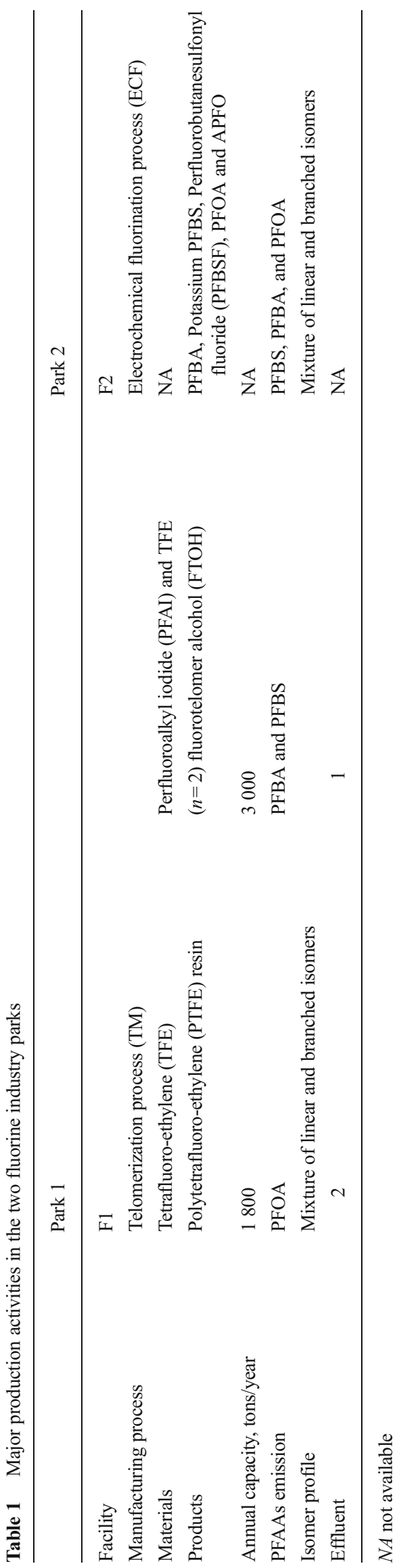


the river is between sites 1 and 14. PFBA and PFBS were also predominant in sediment, followed by PFOA and PFOS. Concentrations ranged from $0.92 \mathrm{ng} / \mathrm{g}$ to $30.4 \mathrm{ng} / \mathrm{g}$ for PFBA and from $0.06 \mathrm{ng} / \mathrm{g}$ to $11.08 \mathrm{ng} / \mathrm{g}$ for PFBS, respectively (Table S7). Since the vapor pressure for ionic PFAAs is limited (Wania 2007), the main partition behavior would be between water and surface sediment. In this study, no samples were taken right in the effluents of the facilities to minimize influence of fresh sources on the calculation of the partition coefficients. For the eight PFCAs, the value of $\log K_{\mathrm{d}}$ was similar among PFBA, PFPeA, PFHxA, and PFHpA, but increased from PFHpA $(1.03 \pm 0.46)$ to PFUnDA $(3.35 \pm 0.70)$ and was proportional to length of the carbon chain from $\mathrm{C} 7$ to C11. The same trend was observed for the three PFSAs, from PFBS $(0.34 \pm 0.61)$ to PFOS $(2.77 \pm 0.67)$ (Fig. 4a, Table S8). The fraction of organic carbon is the dominant parameter influencing sorption of PFAAs to sediment (Higgins and Luthy 2006; Ahrens et al. 2010). The $\log K_{\mathrm{OC}}$ was consistently $2.34 \log$ units greater than $\log K_{\mathrm{d}}$ (Fig. 4b, Table S8), which demonstrated the effect of organic carbon in sediment on sorption of PFAAs quantitatively. There were indeed several minus values of $\log K_{\mathrm{d}}$ for PFBS, which indicated that there would be limited sorption of PFBS to sediment from water without the inclusion of organic carbon. Along the primary route, $\log K_{\mathrm{d}}$ didn't vary much for PFBA, PFOA, and PFBS, but $\log K_{\mathrm{OC}}$ changed apparently, especially in site 3 (Fig. 4c), which was the closest site to the effluent from the facilities. Concentrations of PFBA and PFBS increased dramatically from site 2 to site 3 ; this indicated that water effluent could induce $\operatorname{low} \log K_{\mathrm{OC}}$. Site-specific $\log K_{\mathrm{OC}}$ values of individual PFAAs in this study were overall greater than those in the Haihe River and Qilihai wetland in China (Zhao et al. 2012), Tokyo Bay in Japan (Ahrens et al. 2010), various riverine and lacustrine locations in the USA (Higgins and Luthy 2006), and 21 major rivers, lakes, and canals in the Netherland (Kwadijk et al. 2010) (Table S9) as well as observed during laboratory experiments (Ahrens et al. 2011). The fraction of organic matter in sediments ranged from 0.06 to $6.23 \%$ from site 1 to site 14 (Table S7). There are two main reasons for the relatively large proportion of organic contents in the sediments. Fuxin City is famous for coal industry, and there are still lots of coal mining along the Xihe River, which brought heavy pollution of ash to the river. In the Daling River from Yi County downriver, there is intensive mining of sand in the riverbed. Both activities not only destroy the natural sedimentation process but also make the sediment mix with the water more frequently. This will increase the chance for the sorption of PFAAs to the sediment. Another is that the relatively great concentrations of PFAAs detected in surface water in this study might also increase the absolute amount of PFAAs adsorbed to sediment. More research is needed on the influence of concentrations of PFAAs in water on $\log K_{\mathrm{OC}}$.
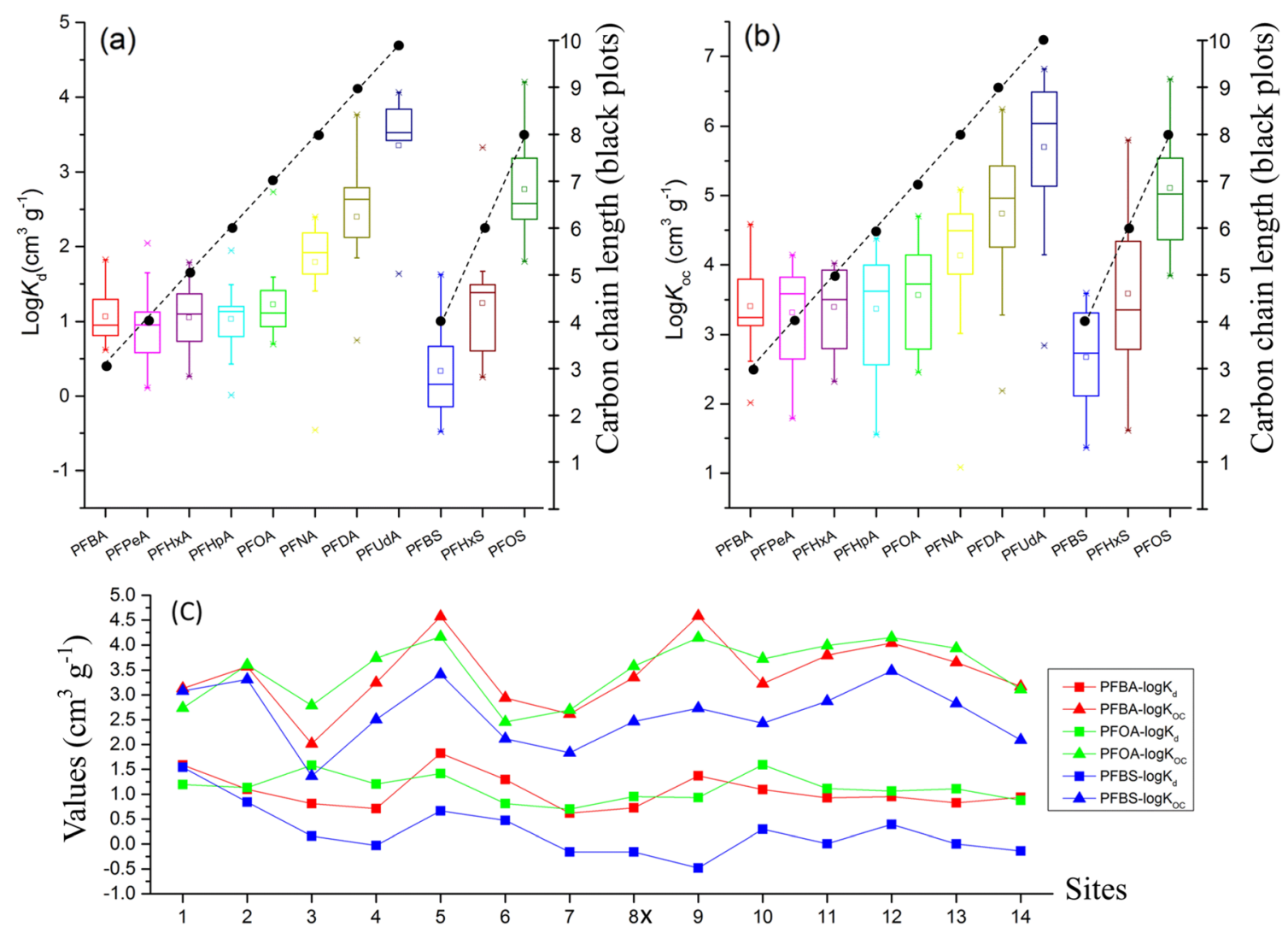

Fig. $4 \log K_{\mathrm{d}}(\mathbf{a})$ and $\log K_{\mathrm{OC}}$ (b) values for 11 PFAAs and the trend of the values for PFBA, PFOA, and PFBS (c) from site 1 to site 14 
Previous studies have focused mostly on regions contaminated by non-point sources of PFAAs, and there is limited information on partitioning behavior of PFAAs near more concentrated, point sources. Therefore, the information reported here would contribute to the modeling of transport and fate of PFAAs at these types of sites.

Each additional $\mathrm{CF}_{2}$ moiety increased the $\log K_{\mathrm{OC}}$ by 0.20 to $0.96 \log$ units for C7 to C11 PFCAs and 0.91 to $1.52 \mathrm{log}$ units for the three PFSAs, respectively (Table S8). For the same carbon chain length between PFCAs and PFSAs, log $K_{\mathrm{OC}}$ of PFBS is $0.64 \log$ units smaller than that of PFPeA, while $\log K_{\mathrm{OC}}$ of PFHxS is $0.22 \log$ units greater than that of PFHpA and $\log K_{\mathrm{OC}}$ of PFOS is $0.98 \log$ units greater than that of PFNA. This indicated that PFSAs are more absorbed to sediment organic carbon than PFCAs with the increasing carbon chain length, especially for PFOS. This trend was also found in previous studies, but the values observed in this study were greater. Besides the local conditions, hydrophobic interaction was found to play a key role in partitioning of longerchain PFAAs, while electrostatic interaction could affect the sorption of short-chain PFAAs to sediments (Zhao et al. 2012). Other parameters, like $\mathrm{Ca}^{2+}, \mathrm{pH}$, heterogeneity of organic carbon, particulate structure, and the presence of organisms have also been reported to influence partitioning of PFAAs between water and sediment, but varies in different natural environment (Higgins and Luthy 2006; Ahrens et al. 2010).

Is there any risk for the short-chain substitutes?

Over last decade, along with the phase-out announcement of longer-chain PFAAs by $3 \mathrm{M}$, numerous studies on the toxicology of PFOS and PFOA have been conducted and PFOS is now listed under the Stockholm Convention, and several countries or regions have put strict control over production, usage, and releases of PFOS and PFOA. Meanwhile, some countries have also established drinking water criteria for PFOS and PFOA, and criteria maximum concentration (CMC) and criteria continuous concentration (CCC) of the two PFAAs have also been derived in China and North America for the protection of fresh water aquatic organisms (Giesy et al. 2010; Yang et al. 2014). The greatest concentration of PFOA (348 ng/L) in this study exceeded the New Jersey guidance value for PFOA in drinking water (40 ng/ L), but was less than the US EPA provisional health index for PFOA (400 ng/L) and the Health Canada drinking water guidance value for PFOA (700 ng/L). For the $\mathrm{C} 4$ substitutes PFBS and PFBA, many studies have found that they are much less accumulated and have less toxic potencies than longerchain PFAAs such as PFOS and PFOA, due to their fast elimination rate in blood of humans and wildlife (NICNAS 2005; Rickard 2009). For example, PFBA takes 5 days and PFBS takes 1 month, on average, to be eliminated in the human body, while for PFOA and PFOS, the time for elimination are 3.8 and 5.4 years, respectively (Betts 2007). However, this does not mean that there is no accumulation of PFBS. In a study on the blood of Swedish women conducted from 1996 to 2010 , concentrations of PFBS increased by $11 \%$ per year and doubled every 6.3 years (Glynn et al. 2012). Results of other studies suggested that PFBS is tightly bound to human albumin with indications of a saturated binding to serum albumin (NICNAS 2005). Based on the mean elimination halflife of PFBS in the human, in Minnesota of USA, where one of the 3 M's largest per/polyfluorinated chemicals production facilities is located, Minnesota Department of Health (MDH) has developed health risk limits for PFBS for groundwater in 2011, including the subchronic noncancer health-risk limit (nHRL) $(9 \mu \mathrm{g} / \mathrm{L})$ and chronic nHRL (7 $\mu \mathrm{g} / \mathrm{L})(\mathrm{MDH} 2011)$. Provisional health-related indication values (HRIV) as safe in drinking water were also derived for PFBA $(7 \mu \mathrm{g} / \mathrm{L})$ and PFBS (3 $\mu \mathrm{g} / \mathrm{L})$ in Germany (Wilhelm et al. 2010). The greatest concentration of PFBS in this study $(2.9 \mu \mathrm{g} / \mathrm{L})$ was slightly less than values reported for HRIV in Germany and was about half or a third of the nHRLs provided by $\mathrm{MDH}$ (Fig. 5). Although the river water is no longer used for drinking, there is intensive farmland along the Xihe and Daling Rivers where the water would be used for irrigation. Field surveys also suggested that individuals still collected fish from the Daling River. Meanwhile, the groundwater could be polluted by the river water through infiltration process, and

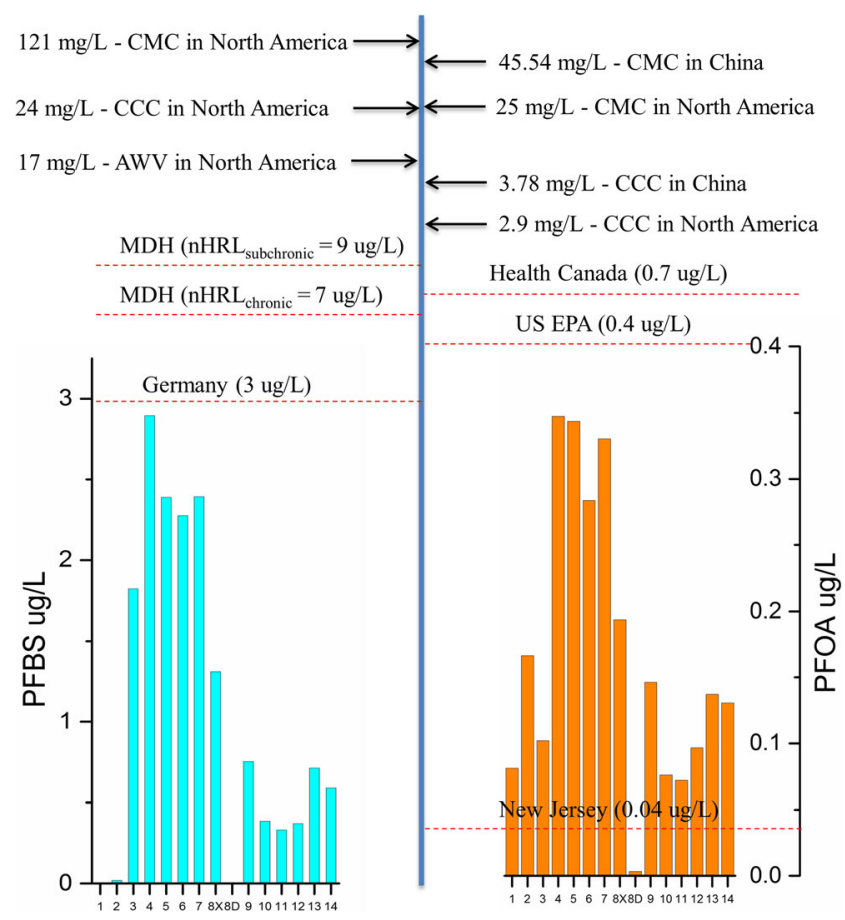

Fig. 5 Comparison of PFAAs concentrations in river water from site 1 to site 14 with criteria values for protection of drinking water (with red dotted line) and aquatic organism in China and other countries (with black arrows). 
groundwater has always been used as drinking water. So, the potential pathway of PFAAs from river water to human through crops, vegetation, fish, and polluted groundwater still existed for local residents. Besides, there are two more health concerns over the PFAAs pollution. One is that FTOHs can form nonvolatile PFSAs and PFCAs through atmospheric transport and degradation (Simcik and Dorweiler 2005). However, the atmospheric pathway would not only influence surface water but also the underlying aquifer by migration downward with precipitation and river recharge (Davis et al. 2007). In 2009 relatively great concentrations of PFAAs had already been detected in groundwater of park 1 (Bao et al. 2010). Another is that PFOA and PFOS can be removed from drinking water by percolation over granular activated carbon, but that technology is ineffective for elimination of shortchain PFAAs (Wilhelm et al. 2010). All concentrations of PFAAs in this study were far below the CCC and CMC values in both China and North America, indicating their low risk to local aquatic ecosystem. However, with fast growing production capacity in the two parks, the potential risk of PFAAs should be listed as one of the health issues by the local government, and long-term monitoring is necessary to make sure that the concentrations are controlled below the criteria.

\section{Conclusions}

This study investigated two fluorine industry parks in northern China. The study area was divided into four sections geographically to give a distinctive expression on the distribution of PFAAs in Daling River Basin. The greatest concentrations of all PFAAs were found in the Xihe River, where the two fluorine industry parks are located. Source identification was made based on concentrations of PFAAs in the river near potential effluents, together with the information on types and volumes of production in the two parks. Results showed that park 1 , where telomerization was used for production, was the major source of linear and branched PFBS, PFBA, and PFOA, while park 2 where ECF applied was the major source of linear and branched PFBS and PFOA. The predominant pathway for transportation of PFAAs was between sites 1 and 14. Partitioning coefficients including $\log K_{\mathrm{d}}$ and $\log$ $K_{\mathrm{OC}}$ were consistent for short-chain PFCAs but increased with increasing chain length for longer-chain PFCAs and PFSAs. This indicated that PFBS and PFBA had a higher transport potential in the water phase than longer chained since they were less removed by sedimentation. Concentrations of individual PFAAs were compared with related criteria for drinking water or for protection of aquatic organisms. The greatest concentration of PFOA exceeded the New Jersey guidance value for drinking water $(40 \mathrm{ng} / \mathrm{L})$. Greatest concentrations of PFBS observed in this study were close to the related guidance values for PFBS, indicating the relatively large risk. However, if the surface water were treated properly and untreated water not consumed, the risks to humans could be minimized, but these measures would not mitigate potential risks to wildlife. With the growing global demand for fluoropolymer, the production capacity in the two parks will increase. Long-term and systematic monitoring is needed on emissions of PFAAs in the two parks, and their environmental behavior in the Daling River Basin or even a larger region. Potential risks posed by PFAAs intake to the health of the local residents and wildlife should become one of the major issues of great concern for the local government.

Acknowledgement This study was supported by the National Natural Science Foundation of China (no. 41371488 and 41171394), the Key Research Program of the Chinese Academy of Sciences (no. KZZDEW-TZ-12), and the International Scientific Cooperation Program with Grant No. 2012DFA91150. Prof. Giesy was supported by the Canada Research Chair Program. We would like to thank the editors and reviewers for their valuable comments and suggestions.

\section{References}

3M (2000) Phase-out plan for PFOS-based products. USEPA Docket, U.S. Environmental Protection Agency

Ahrens L, Taniyasu S, Yeung LWY, Yamashita N, Lam PKS, Ebinghaus R (2010) Distribution of polyfluoroalkyl compounds in water, suspended particulate matter and sediment from Tokyo Bay, Japan. Chemosphere 79(3):266-272

Ahrens L, Yeung LWY, Taniyasu S, Lam PKS, Yamashita N (2011) Partitioning of perfluorooctanoate (PFOA), perfluorooctane sulfonate (PFOS) and perfluorooctane sulfonamide (PFOSA) between water and sediment. Chemosphere 85(5):731-737

Armitage JM, MacLeod M, Cousins IT (2009) Comparative assessment of the global fate and transport pathways of long-chain perfluorocarboxylic acids (PFCAs) and perfluorocarboxylates (PFCs) emitted from direct sources. Environ Sci Technol 43(15): $5830-5836$

Bao J, Liu W, Liu L, Jin Y, Dai J, Ran X, Zhang Z, Tsuda S (2010) Perfluorinated compounds in the environment and the blood of residents living near fluorochemical plants in Fuxin, China. Environ Sci Technol 45(19):8075-8080

Betts KS (2007) Perfluoroalkyl acids: what is the evidence telling us? Environ Health Perspect 115(5):A250-A256

Buck RC, Franklin J, Berger U, Conder JM, Cousins IT, de Voogt P, Jensen AA, Kannan K, Mabury SA, van Leeuwen SPJ (2011) Perfluoroalkyl and polyfluoroalkyl substances in the environment: terminology, classification, and origins. Integr Environ Assess Manag 7(4):513-541

Calafat AM, Wong LY, Kuklenyik Z, Reidy JA, Needham LL (2007) Polyfluoroalkyl chemicals in the U.S. population: data from the National Health and Nutrition Examination Survey (NHANES) 2003-2004 and comparisons with NHANES 1999-2000. Environ Health Perspect 115(11):1596-1602

Codling G, Vogt A, Jones PD, Wang T, Wang P, Lu YL, Corcoran M, Bonina S, Li A, Sturchio NC, Rockne KJ, Ji K, Khim J-S, Naile JE, Giesy JP (2014) Historical trends of inorganic and organic fluorine in sediments of Lake Michigan. Chemosphere 114:203-209

Conder JM, Hoke RA, Wolf W, Russell MH, Buck RC (2008) Are PFCAs bioaccumulative? A critical review and comparison with 
regulatory criteria and persistent lipophilic compounds. Environ Sci Technol 42(4):995-1003

Davis KL, Aucoin MD, Larsen BS, Kaiser MA, Hartten AS (2007) Transport of ammonium perfluorooctanoate in environmental media near a fluoropolymer manufacturing facility. Chemosphere 67(10): 2011-2019

EC (2006) Directive 2006/122/EC of the European Parliament and of the Council of 12 December 2006 amending for the 30th time Council Directive 76/769/EEC on the approximation of the laws, regulations and administrative provisions of the member states relating to restrictions on the marketing and use of certain dangerous substances and preparations (perfluorooctane sulfonates)

Eschauzier C, Raat KJ, Stuyfzand PJ, De Voogt P (2013) Perfluorinated alkylated acids in groundwater and drinking water: identification, origin and mobility. Sci Total Environ 458-460:477-485

European Commission (2010) Analysis of the risks arising from the industrial use of perfuorooctanoic acid (PFOA) and ammonium perfluorooctanoate (APFO) and from their use in consumer articles. Evaluation of the risk reduction measures for potential restrictions on the manufacture, placing on the market and use of PFOA and APFO. http://ec.europa.eu/enterprise/sectors/chemicals/files/docs studies/final_report_pfoa_pfos_en.pdf. (July 25 2014)

Fuxin Fluorine Industry Development Zone (2012) http://www.f-china. gov.cn. (July 25 2014)

Giesy JP, Naile JE, Khim JS, Jones PD, Newsted JL (2010) Aquatic toxicology of perfluorinated chemicals. In: Whitacre DM (ed) Reviews of environmental contamination and toxicology, Vol 202. Springer, New York, pp 1-52

Glynn A, Berger U, Bignert A, Ullah S, Aune M, Lignell S, Darnerud PO (2012) Perfluorinated alkyl acids in blood serum from primiparous women in Sweden: serial sampling during pregnancy and nursing, and temporal trends 1996-2010. Environ Sci Technol 46(16):90719079

Higgins CP, Luthy RG (2006) Sorption of perfluorinated surfactants on sediments $\uparrow$. Environ Sci Technol 40(23):7251-7256

Holt R (2011) The influence of global regulatory changes and customer preferences on the development of alternatves to long chain fluorinated chemicals. DuPont for FluoroCouncil

Houde M, De Silva AO, Muir DCG, Letcher RJ (2011) Monitoring of perfluorinated compounds in aquatic biota: an updated review. Environ Sci Technol 45(19):7962-7973

POPs Action in China (2014) http://www.china-pops.org. (July 25 2014)

Kwadijk CJAF, Korytár P, Koelmans AA (2010) Distribution of perfluorinated compounds in aquatic systems in The Netherlands. Environ Sci Technol 44(10):3746-3751

Kwok KY, Taniyasu S, Yeung LWY, Murphy MB, Lam PKS, Horii Y, Kannan K, Petrick G, Sinha RK, Yamashita N (2010) Flux of perfluorinated chemicals through wet deposition in Japan, the United States, and several other countries. Environ Sci Technol 44(18): 7043-7049

Lau C, Anitole K, Hodes C, Lai D, Pfahles-Hutchens A, Seed J (2007) Perfluoroalkyl acids: a review of monitoring and toxicological findings. Toxicol Sci 99(2):366-394

Lindstrom AB, Strynar MJ, Libelo EL (2011) Polyfluorinated compounds: past, present, and future. Environ Sci Technol 45(19): 7954-7961

Loi EIH, Yeung LWY, Taniyasu S, Lam PKS, Kannan K, Yamashita N (2011) Trophic magnification of poly- and perfluorinated compounds in a subtropical food web. Environ Sci Technol 45(13): $5506-5513$

MDH (2011) 2011 Health Risk Limits for Groundwater. http://www. health.state.mn.us/divs/eh/risk/guidance/gw/table.html. (July 25 2014)

Moller A, Ahrens L, Surm R, Westerveld J, van der Wielen F, Ebinghaus R, de Voogt P (2010) Distribution and sources of polyfluoroalkyl substances (PFAS) in the River Rhine watershed. Environ Pollut 158(10):3243-3250

NICNAS (2005) POTASSIUM PERFLUOROBUTANE SULFONATE: HAZARD ASSESSMENT. http://www.nicnas.gov.au/ data/ assets/pdf file/0004/4927/Potassium Perfluorobutane Sulfonate PDF.pdf. (July 25 2014)

Oliaei F, Kriens D, Weber R, Watson A (2013) PFOS and PFC releases and associated pollution from a PFC production plant in Minnesota (USA). Environ Sci Pollut R 20(4):1977-1992

Olsen GW, Chang SC, Noker PE, Gorman GS, Ehresman DJ, Lieder PH, Butenhoff JL (2009) A comparison of the pharmacokinetics of perfluorobutanesulfonate (PFBS) in rats, monkeys, and humans. Toxicology 256(1-2):65-74

Olsen GW, Lange CC, Ellefson ME, Mair DC, Church TR, Goldberg CL, Herron RM, Medhdizadekashi Z, Nobiletti JB, Rios JA, Reagen WK, Zobel LR (2012) Temporal trends of perfluoroalkyl concentrations in American Red Cross Adult Blood Donors, 2000 - 2010. Environ Sci Technol 46(11):6330-6338

Pan YY, Shi YL, Wang JM, Jin XL, Cai YQ (2011) Pilot investigation of perfluorinated compounds in river water, sediment, soil and fish in Tianjin, China. Bull Environ Contam Toxicol 87(2):152-157

Paul AG, Jones KC, Sweetman AJ (2009) A first global production, emission, and environmental inventory for perfluorooctane sulfonate. Environ Sci Technol 43(2):386-392

Prevedouros K, Cousins IT, Buck RC, Korzeniowski SH (2006) Sources, fate and transport of perfluorocarboxylates. Environ Sci Technol 40(1):32-44

Rickard RW (2009) Toxicology-perfluorocarboxylates-PFOA-PFHxAPFBA (J. Butenhoff). http://www.epa.gov/oppt/pfoa/pubs/ Toxicology-Carboxylates\%20-Rickard.pdf. (July 25 2014)

Simcik MF, Dorweiler KJ (2005) Ratio of perfluorochemical concentrations as a tracer of atmospheric deposition to surface waters. Environ Sci Technol 39(22):8678-8683

Taniyasu S, Kannan K, So MK, Gulkowska A, Sinclair E, Okazawa T, Yamashita N (2005) Analysis of fluorotelomer alcohols, fluorotelorner acids, and short- and long-chain perfluorinated acids in water and biota. J Chromatogr A 1093(1-2):89-97

UNEP (2009) The conference of the parties 4 of the Stockholm Convention (COP-4) in Geneva placed perfluorooctane sulfonate and perfluorooctane sulfonyl fluoride (PFOS and PFOSF) in Annex B. http://chm.pops.int/Convention/Pressrelease/ COP4Geneva9May2009/tabid/542/language/en-US/Default.aspx. (July 25 2014)

USEPA (2006) 2010/2015 PFOA Stewardship Program. http://www.epa. gov/opptintr/pfoa/pubs/stewardship/. (July 25 2014)

Wang TY, Lu YL, Chen CL, Naile JE, Khim JS, Park J, Luo W, Jiao WT, Hu WY, Giesy JP (2011) Perfluorinated compounds in estuarine and coastal areas of north Bohai Sea, China. Mar Pollut Bull 62(8): 1905-1914

Wang B, Cao M, Zhu H, Chen J, Wang L, Liu G, Gu X, Lu X (2013a) Distribution of perfluorinated compounds in surface water from Hanjiang River in Wuhan, China. Chemosphere 93(3):468-473

Wang P, Wang TY, Giesy JP, Lu YL (2013b) Perfluorinated compounds in soils from Liaodong Bay with concentrated fluorine industry parks in China. Chemosphere 91(6):751-757

Wang P, Lu Y, Wang T, Fu Y, Zhu Z, Liu S, Xie S, Xiao Y, Giesy JP (2014a) Occurrence and transport of 17 perfluoroalkyl acids in 12 coastal rivers in south Bohai coastal region of China with concentrated fluoropolymer facilities. Environ Pollut 190:115-122

Wang T, Wang P, Meng J, Liu S, Lu Y, Khim JS, Giesy JP (2014b) A review of sources, multimedia distribution and health risks of perfluoroalkyl acids (PFAAs) in China. Chemosphere. doi:10.1016/j.chemosphere.2014.09.021 
Wania F (2007) A global mass balance analysis of the source of perfluorocarboxylic acids in the Arctic ocean. Environ Sci Technol 41(13):4529-4535

Wilhelm M, Bergmann S, Dieter HH (2010) Occurrence of perfluorinated compounds (PFCs) in drinking water of North Rhine-Westphalia, Germany and new approach to assess drinking water contamination by shorter-chained C4-C7 PFCs. Int J Hyg Environ Health 213(3): 224-232

Xie S, Lu Y, Wang T, Liu S, Jones K, Sweetman A (2013a) Estimation of PFOS emission from domestic sources in the eastern coastal region of China. Environ Int 59:336-343

Xie SW, Wang TY, Liu SJ, Jones KC, Sweetman AJ, Lu YL (2013b) Industrial source identification and emission estimation of perfluorooctane sulfonate in China. Environ Int 52:1-8
Yang S, Xu F, Wu F, Wang S, Zheng B (2014) Development of PFOS and PFOA criteria for the protection of freshwater aquatic life in China. Sci Total Environ 470-471:677-683

Zhao L, Zhu L, Yang L, Liu Z, Zhang Y (2012) Distribution and desorption of perfluorinated compounds in fractionated sediments. Chemosphere 88(11):1390-1397

Zhou Z, Liang Y, Shi Y, Xu L, Cai Y (2013) Occurrence and transport of perfluoroalkyl acids (PFAAs), including shortchain pfaas in Tangxun Lake, China. Environ Sci Technol 47(16):9249-9257

Zhou Z, Shi Y, Vestergren R, Wang T, Liang Y, Cai Y-Q (2014) Highly elevated serum concentrations of perfluoroalkyl substances in fishery employees from Tangxun Lake, China. Environ Sci Technol 48(7):3864-3874 